\title{
Effect of Switching to Azilsartan From Fixed-Dose Combination of an Angiotensin II Receptor Blocker and Calcium Channel Blocker or a Thiazide in Patients With Hypertension
}

\author{
Toru Miyoshi ${ }^{\mathrm{a}, \mathrm{c}}$, Go Onoue ${ }^{\mathrm{b}}$, Hiroshi Ito ${ }^{\mathrm{a}}$
}

\begin{abstract}
Background: Despite the availability of antihypertensive treatments, fewer than half of patients who receive treatment successfully achieve blood pressure (BP) goals. The purpose of this study was to evaluate the effect of switching to azilsartan $40 \mathrm{mg}$ from a fixed-dose combination tablet of an angiotensin II receptor blocker (ARB) and amlodipine at $5 \mathrm{mg}$ or azelnidipine at $16 \mathrm{mg}(\mathrm{ARB} / \mathrm{CCB})$ or an $\mathrm{ARB}$ and hydrochlorothiazide (HCT) at $6.25 \mathrm{mg}$ or $12.5 \mathrm{mg}(\mathrm{ARB} / \mathrm{HCT})$ on BP.
\end{abstract}

Methods: This prospective, multicenter, open-labeled, single-arm study included 40 patients treated with a fixed-dose combination tablet of an $\mathrm{ARB} / \mathrm{CCB}$ or an $\mathrm{ARB} / \mathrm{HCT}$, which was switched to azilsar$\tan 40 \mathrm{mg}$ after enrollment. The primary outcome was the change in BP from baseline to the 24-week follow-up.

Results: Of the 40 patients who completed this study, 33 did not require changes in their antihypertensive medications after switching to azilsartan, and their BP did not change from baseline to follow-up. However, the systolic BP in seven patients was elevated at 12 weeks, and amlodipine at $5 \mathrm{mg}$ was therefore added; these patients' baseline medications were an $\mathrm{ARB} / \mathrm{CCB}(\mathrm{n}=6)$ and an ARB/HCT $(\mathrm{n}=1)$. In all patients, the serum potassium level was slightly increased after switching to azilsartan at 6 months, while the serum creatinine, hemoblobinA1c, and lipid profile did not change.

Conclusions: Azilsartan at $40 \mathrm{mg}$ did not result in a greater decrease in $\mathrm{BP}$ than a fixed-dose combination tablet of an $\mathrm{ARB} / \mathrm{CCB}$ or an ARB/HCT. However, our findings suggest a substantial BP-lowering effect of azilsartan at $40 \mathrm{mg}$ in patients with hypertension.

Keywords: Azilsartan; Blood pressure; Calcium channel blocker; Diuretic; Clinical trial

Manuscript submitted December 15, 2018, accepted December 31, 2018

a Department of Cardiovascular Medicine, Okayama University Graduate School of Medicine, Dentistry and Pharmaceutical Sciences, Okayama, Japan bonoue Clinic, Okayama, Japan

${ }^{\mathrm{c} C o r r e s p o n d i n g ~ A u t h o r: ~ T o r u ~ M i y o s h i, ~ D e p a r t m e n t ~ o f ~ C a r d i o v a s c u l a r ~ M e d i-~}$ cine, Okayama University, 2-5-1 Shikata-cho, Kita-ku, Okayama 700-8558, Japan. Email: miyoshit@cc.okayama-u.ac.jp

doi: https://doi.org/10.14740/jocmr3723

\section{Introduction}

Despite the availability of antihypertensive treatments, hypertension remains inadequately controlled and does not meet the recommended blood pressure (BP) goals [1]. New hypertension guidelines from the United States and Europe state that the recommended BP target in adults requiring drug treatment was changed from $140 / 90$ to $130 / 80 \mathrm{~mm} \mathrm{Hg}$ in those $<65$ years of age $[2,3]$. Thus, the availability of antihypertensive drugs that will substantially reduce BP is likely to promote improved BP control rates.

Azilsartan, a long-acting angiotensin II receptor blocker (ARB), reportedly has greater antihypertensive effects than other ARBs [4-6]. In one study, azilsartan at $80 \mathrm{mg}$ had superior efficacy to both valsartan at $320 \mathrm{mg}$ and olmesartan at $40 \mathrm{mg}$, and azilsartan at $40 \mathrm{mg}$ was noninferior to olmesartan at $40 \mathrm{mg}$ [5]. Several studies have shown that azilsartan has pleiotropic effects such as improvement in cardiometabolic parameters [7-10]. Thus, azilsartan is a promising ARB for primary and secondary prevention of cardiovascular disease.

While many drug classes are available to reduce BP, the use of ARBs has become a popular strategy in the management of hypertension. In addition, in patients with uncontrolled hypertension using three or more antihypertensive drugs, the strong BP-lowering effect of each drug could provide higher rates of hypertension control. According to previous studies of azilsartan [4-6] and a fixed-dose tablet of an ARB and a calcium channel blocker (CCB) or an ARB and a diuretic at the usual dose in Japan [11-14], we hypothesized that azilsartan at $40 \mathrm{mg}$ is more efficacious than these combination therapies. The purpose of this study was to evaluate the effect of azilsartan at $40 \mathrm{mg}$ after switching from a fixed-dose combination tablet of an ARB at the usual dose in Japan and a CCB or hydrochlorothiazide (HCT) on BP.

\section{Materials and Methods}

\section{Ethical considerations}

The study was approved by the ethics committees of all partic- 


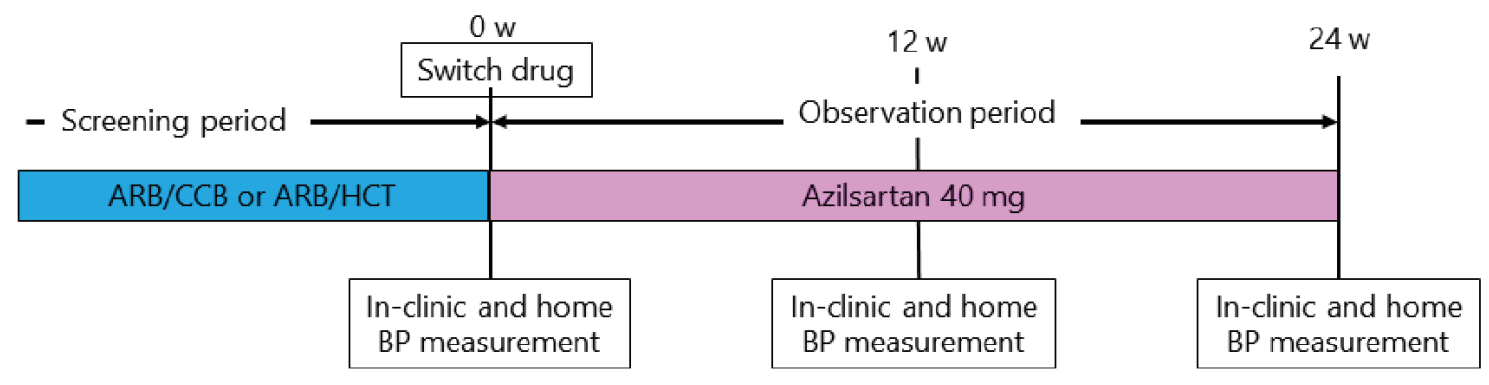

Figure 1. Study protocol. ARB/CCB: angiotensin II receptor blocker and amlodipine $5 \mathrm{mg}$ or azelnidipine $16 \mathrm{mg}$; AEB/HCT: angiotensin II receptor blocker and hydrochlorothiazide $6.25 \mathrm{mg}$ or $12.5 \mathrm{mg}$; BP: blood pressure.

ipating hospitals and clinics. All participants provided written informed consent before enrollment. This study was conducted according to the principles expressed in the Declaration of Helsinki. The study is registered in the UMIN Clinical Trials Registry (UMIN000012587).

\section{Patient population}

Participants were enrolled at 11 affiliated hospitals or clinics of Okayama University in Japan from July 2012 to June 2014. Eligible patients were adults ( $>30$ to $<85$ years old) who were undergoing treatment with a combination tablet including the usual dose of an ARB (excluding azilsartan) and the usual dose of a CCB or diuretic. Patients with the following conditions were excluded: secondary hypertension, grade III hypertension according to the Japanese Society of Hypertension 2009 guideline [15], congestive heart failure, severe valvular heart disease, myocardial infarction or cerebellar infarction within 6 months, chronic atrial fibrillation, malignant arrhythmia, renal insufficiency (serum creatinine concentration of $\geq 2 \mathrm{mg} / \mathrm{dL}$ ), severe liver disease, chronic inflammatory disease, malignant disease (lifetime prognosis of $<6$ months), and treatment with a renin-angiotensin system inhibitor other than an ARB.

\section{Study protocol}

This study was a 24-week, prospective, multicenter openlabel study with a single treatment arm (Fig. 1). Before enrollment, eligible patients received a fixed-dose tablet of an $\mathrm{ARB}$ and amlodipine at $5 \mathrm{mg}$ or azelnidipine at $16 \mathrm{mg}$ (ARB/ $\mathrm{CCB}$ ) or a fixed-dose tablet of an ARB and HCT at 6.25 or $12.5 \mathrm{mg}(\mathrm{ARB} / \mathrm{HCT})$ in which azilsartan was not the ARB. The baseline $\mathrm{ARB} / \mathrm{CCB}$ and $\mathrm{ARB} / \mathrm{HCT}$ treatments are shown in Table 1. At the time of enrollment, the fixed-dose tablet was switched to azilsartan at $40 \mathrm{mg}$. After 12 weeks, addition of amlodipine at $5 \mathrm{mg}$ was permitted according to the physician's decision if BP control was poor after switching to azilsartan. Treatment was continued for 24 weeks. Other drugs that could potentially interfere with the efficacy of the study medications were not allowed. All patients were re- viewed for general health and compliance with medication, which was assessed by tablet counts and BP checks at each clinic visit.

The primary outcome was the change in clinic BP after treatment with azilsartan at $40 \mathrm{mg}$ for 24 weeks.

\section{Measurement of in-clinic and home BPs}

In-clinic BP and heart rate were measured in a sitting position three times at 1-min intervals using a validated oscillometric device after an initial 5 min of seated rest [16]. Home BP and heart rate were measured in a sitting position three times each morning and three times each evening for 5 consecutive days before the clinic visit (total of three visits) using a validated oscillometric device. The mean BP for 5 consecutive days was determined as the home BP. The patients were instructed to rest for $5 \mathrm{~min}$ before the first reading and rest for a 15 -s interval between readings. Morning BP was measured within $1 \mathrm{~h}$ after waking, after urination, and before breakfast according to the Japanese home BP guidelines [17].

\section{Blood sampling}

Blood samples were collected from an antecubital vein after a 12-h overnight fast and after a rest of at least $30 \mathrm{~min}$ with the patient in the supine position. Routine biochemical parameters, including glycated hemoglobin and the serum concentrations of total cholesterol, high-density lipoprotein cholesterol, low-density lipoprotein cholesterol, triglycerides, creatine, and uric acid, were measured immediately using an autoanalyzer.

\section{Sample size}

We hypothesized that the in-clinic systolic BP would be lower at 24 weeks than at baseline. We assumed a mean difference in the in-clinic systolic BP of $5 \mathrm{~mm} \mathrm{Hg}$, with a standard deviation of $12 \mathrm{~mm} \mathrm{Hg}$. Using a two-sided paired test for differences, a minimum sample size of 58 patients was required to detect statistically significant differences in systolic BP with a power 
Table 1. Patients' Characteristics

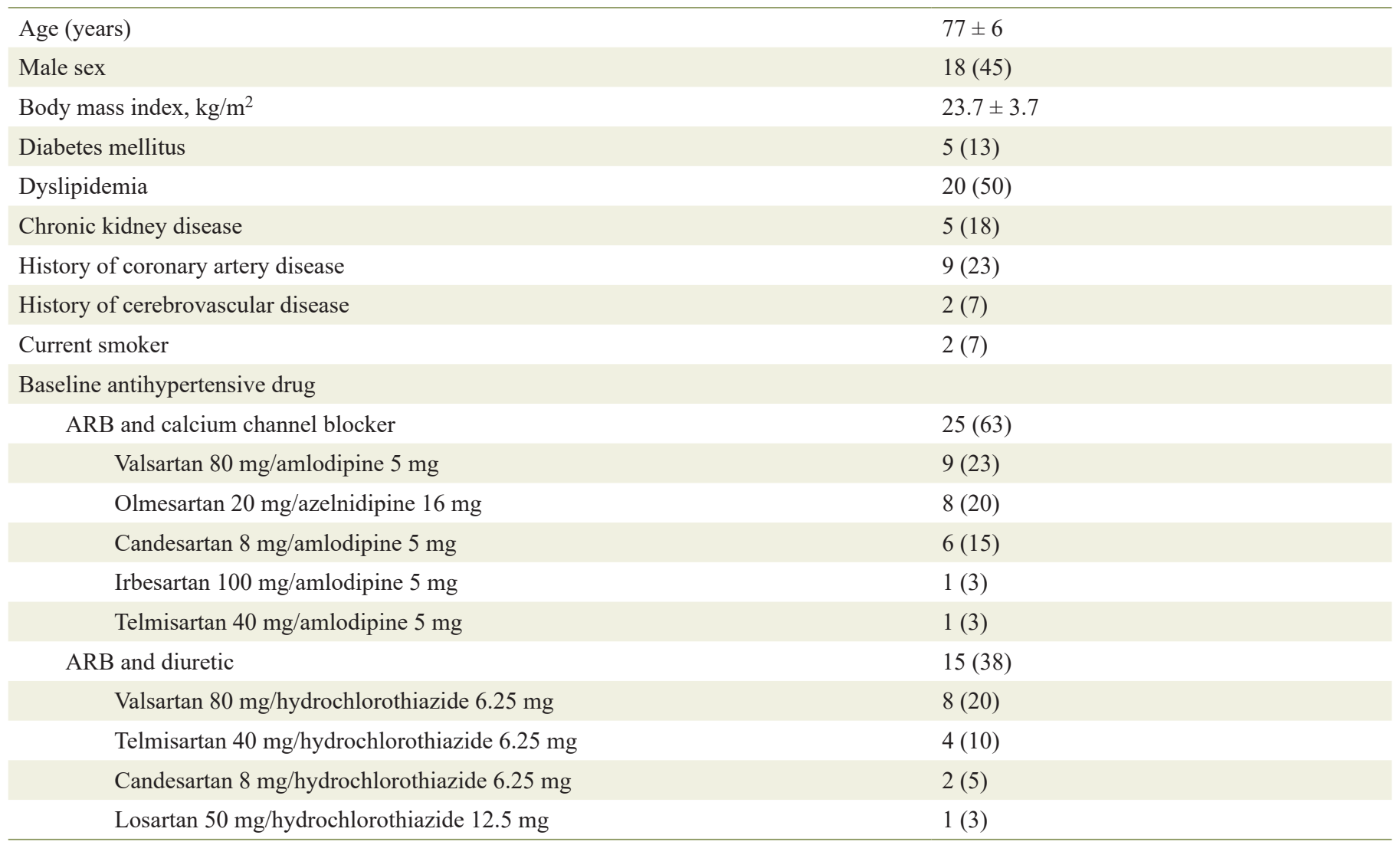

Data are presented as mean \pm standard deviation or $\mathrm{n}(\%)$. ARB: angiotensin II receptor blocker.

of $80 \%$ and an $\alpha$-type error of $5 \%$.

\section{Statistical analysis}

Continuous variables are presented as mean \pm standard deviation, and categorical variables are presented as absolute value and proportion (\%). Comparisons between two groups were performed by a paired $t$-test. Variables at baseline, 12 weeks, and 24 weeks were compared using one-way repeated analysis of variance followed by the Bonferroni post hoc analysis. A P value of $<0.05$ was considered statistically significant. Statistical analyses were performed using SPSS 24.0 for Windows (IBM Corp., Armonk, NY, USA).

\section{Results}

\section{Characteristics of the study participants}

In total, 47 patients were enrolled in this study. Of these patients, 40 completed the study (seven patients were lost to follow-up). The baseline characteristics of these 40 patients are shown in Table 1 . Their mean age was 77 years, and $45 \%$ were men. The proportion of patients with diabetes mellitus and dyslipidemia were $13 \%$ and $50 \%$, respectively. The baseline fixed-dose combination tablet was an ARB/CCB in $63 \%$ of patients and an ARB/HCT in $38 \%$.

\section{Change in BP after switching to azilsartan}

In all patients, the in-clinic and home BPs did not change significantly between baseline and follow-up (Table 2). A total of 33 patients $(84 \%)$ completed this study without adding amlodipine after switching to azilsartan (Fig. 2). Their inclinic and home BPs did not change during the study period. However, in seven patients $(16 \%)$, systolic BP was elevated at 12 weeks and amlodipine at $5 \mathrm{mg}$ was therefore added (Table 2). The patients' baseline combination drugs were candesartan at $8 \mathrm{mg} /$ amlodipine at $5 \mathrm{mg}(\mathrm{n}=3)$, olmesartan at $20 \mathrm{mg}$ /azelnidipine at $16 \mathrm{mg}(\mathrm{n}=2)$, telmisartan at $40 \mathrm{mg} /$ amlodipine at $5 \mathrm{mg}(\mathrm{n}=1)$, and telmisartan at $40 \mathrm{mg} / \mathrm{HCT}$ at $6.25 \mathrm{mg}(\mathrm{n}=1)$. Thus, among the seven patients whose BP was increased at 12 weeks, six patients had taken an ARB/ $\mathrm{CCB}$ at baseline. The elevated systolic BP at 12 weeks significantly decreased after adding amlodipine at $5 \mathrm{mg}$ (Table 2).

The changes in the patients' biochemical parameters are shown in Table 3 . The serum potassium level significantly increased after switching to azilsartan for 24 weeks, while the 
Table 2. Change in Blood Pressure

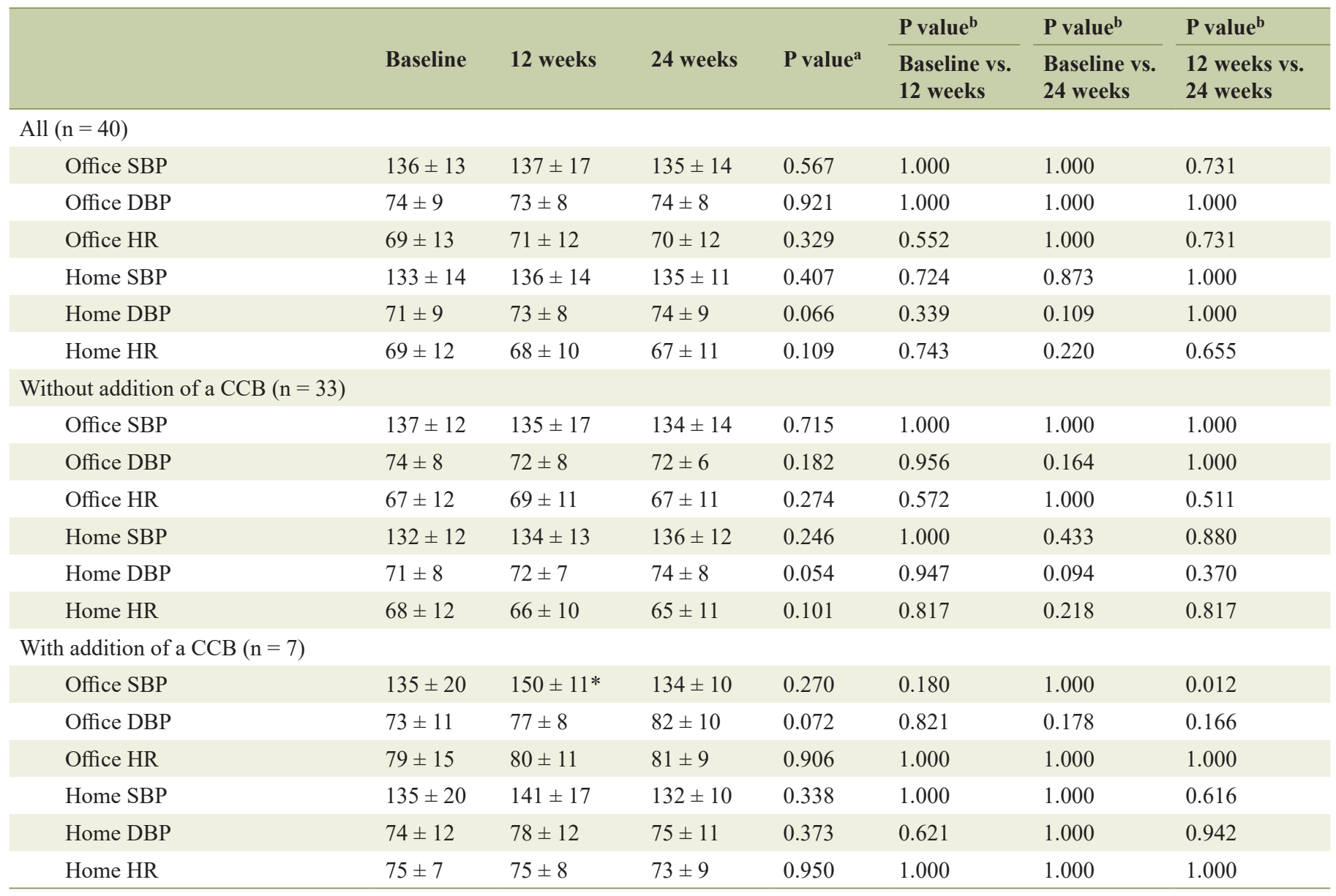

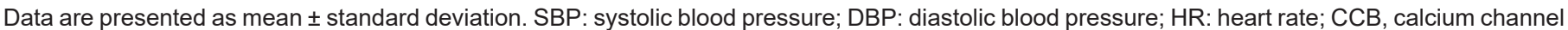
blocker. aP value by one-way repeated analysis of variance. ${ }^{\text {bP }}$ value by the Bonferroni post hoc analysis. ${ }^{*} \mathrm{P}<0.05$ vs. at 24 weeks.

other parameters did not change.

\section{Discussion}

This study demonstrated that switching to azilsartan at $40 \mathrm{mg}$ from a fixed-dose combination tablet of an $\mathrm{ARB} / \mathrm{CCB}$ or an $\mathrm{ARB} / \mathrm{HCT}$ did not decrease the in-clinic or home BP. After switching to azilsartan at $40 \mathrm{mg}$, an increase in BP was observed in $16 \%$ of patients at 12 weeks. Our findings suggest that azilsartan at $40 \mathrm{mg}$ has substantial efficacy in lowering BP, similar to a fixed-dose combination tablet of an $\mathrm{ARB} / \mathrm{CCB}$ or an $\mathrm{ARB} / \mathrm{HCT}$.

Several studies have revealed the BP-lowering efficacy of azilsartan. Rakugi et al [4] reported that treatment with azilsartan at 20 to $40 \mathrm{mg}$ reduced systolic BP by $21.8 \mathrm{~mm} \mathrm{Hg}$. White et al [5] also reported that treatment with azilsartan at $40 \mathrm{mg}$ for 6 weeks reduced systolic BP by $15 \mathrm{~mm} \mathrm{Hg}$. Regarding the effect of combination therapy of an $\mathrm{ARB} / \mathrm{CCB}$ or an ARB/HCT, Shimosawa et al [18] reported that treatment with candesartan at $8 \mathrm{mg} /$ amlodipine at $5 \mathrm{mg}$ for 16 weeks reduced systolic BP by $20 \mathrm{~mm} \mathrm{Hg}$. McInnes et al [19] reported that treatment with candesartan at $8 \mathrm{mg} / \mathrm{HCT}$ at $12.5 \mathrm{mg}$ for 26 weeks reduced systolic BP by $16.2 \mathrm{~mm} \mathrm{Hg}$ in patients with grade I to II essential hypertension. These studies suggest that azilsartan at $40 \mathrm{mg}$ has a capability of reducing BP similar to that of combination therapy of an $\mathrm{ARB} / \mathrm{CCB}$ or an $\mathrm{ARB} / \mathrm{HCT}$. Although the present study did not prove the hypothesis that azilsartan at $40 \mathrm{mg}$ is more efficacious than these combination therapies, the substantial BP-lowering effect of azilsartan at 40 mg was appreciated.

An increase in adverse events during this short-term trial was not observed. Laboratory findings did not suggest any clinically relevant changes in renal function or serum mineral homeostasis secondary to azilsartan. In addition, several studies have shown a powerful BP-lowering effect and high safety of azilsartan when used with a CCB or a diuretic in patients with hypertension. According to the 2017 American College of Cardiology/American Heart Association guidelines, the prevalence of hypertension among adults in the United States was $45.6 \%$, and $53.4 \%$ of patients taking antihypertensive medication had BP above the treatment goal [20]. This finding indicates that half of the population with hypertension remains at risk for cardiovascular events. Because the efficacy and toler- 
Patients who completed this study $(\mathrm{N}=40)$

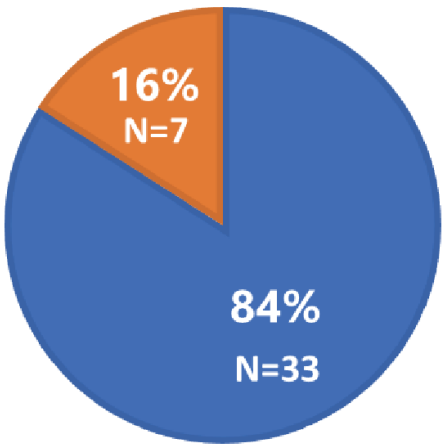

Patients in whom amlodipine was not added $(n=33)$

Patients in whom amlodipine was added $(n=7)$

Figure 2. Proportion of patients for whom amlodipine at $5 \mathrm{mg}$ was and was not added at 12 weeks.

ability of antihypertensive drug therapy play an important role in control of hypertension, azilsartan could lead to enhanced $\mathrm{BP}$ control in patients with hypertension.

\section{Limitations}

This study had several limitations. First, it was an open-labeled, single-arm trial and may thus have potentially biased results. Additionally, the sample size was small. Therefore, a larger trial is required to verify our conclusion. Second, the planned sample size was not achieved, and the study may have been underpowered. However, considering the small difference in BP between baseline and 24 weeks, it would be difficult to achieve statistical significance even if the enrollment was completed. This may mitigate the influence of the lowerpowered statistical test on the conclusion of the study.

\section{Conclusions}

Azilsartan at $40 \mathrm{mg}$ did not result in a greater decrease in BP than a fixed-dose combination tablet of an $\mathrm{ARB} / \mathrm{CCB}$ or an $\mathrm{ARB} / \mathrm{HCT}$. However, our findings suggest a substantial BPlowering effect of azilsartan at $40 \mathrm{mg}$, which could lead to a reduction in the number of patients with $\mathrm{BP}$ above the treatment goal.

\section{Acknowledgments}

The authors sincerely thank Dr. Mitsuru Tokisue, Dr. Akira Fushimi, Dr. Keishiro Maki, Dr. Yoshihiro Nishihara, Dr. Tetsushi Seito, Dr. Tomoyoshi Iwado, Dr. Atsushi Hirohata, Dr. Junko Tomita, and Dr. Naoki Kondo for recruiting participants for this study. The authors also thank Angela Morben, DVM, ELS, from Edanz Group (www.edanzediting.com/ac), for editing a draft of this manuscript.
Table 3. Change in Biochemical Parameters

\begin{tabular}{llll}
\hline & Baseline & 6 months & P value \\
\hline $\mathrm{Na}(\mathrm{mEq} / \mathrm{L})$ & $140.2 \pm 1.7$ & $140.0 \pm 2.9$ & 0.429 \\
$\mathrm{~K}(\mathrm{mEq} / \mathrm{L})$ & $4.2 \pm 0.4$ & $4.4 \pm 0.5$ & 0.013 \\
$\mathrm{Cl}(\mathrm{mEq} / \mathrm{L})$ & $103.3 \pm 5.8$ & $103.2 \pm 2.9$ & 0.367 \\
$\mathrm{BUN}(\mathrm{mg} / \mathrm{dL})$ & $20.2 \pm 6.1$ & $19.5 \pm 6.9$ & 0.847 \\
Serum creatinine (mg/dL) & $0.87 \pm 0.20$ & $0.98 \pm 0.34$ & 0.115 \\
Hemoglobin A1c $(\%)$ & $5.9 \pm 0.6$ & $5.8 \pm 0.7$ & 0.167 \\
Triglyceride $(\mathrm{mg} / \mathrm{dL})$ & $96.7 \pm 41.9$ & $112.2 \pm 30.6$ & 0.916 \\
LDL-cholesterol $(\mathrm{mg} / \mathrm{dL})$ & $98.3 \pm 36.9$ & $94.5 \pm 24.6$ & 0.572 \\
HDL-cholesterol (mg/dL) & $62.9 \pm 13.6$ & $56.8 \pm 12.7$ & 0.086 \\
Uric acid (mg/dL) & $5.4 \pm 1.3$ & $5.8 \pm 1.8$ & 0.630 \\
\hline
\end{tabular}

Data are presented as mean \pm standard deviation. Na: sodium; K: potassium; Cl: chloride; BUN: blood urea nitrogen; LDL: low-density lipoprotein; HDL: high-density lipoprotein.

\section{Funding}

This work was partly supported by Takeda Pharmaceutical Co.

\section{Conflict of Interest}

TM and HI received honoraria from Takada Pharmaceutical Co. The other authors have no conflicts of interest in relation to the materials presented in this article.

\section{References}

1. Mills KT, Bundy JD, Kelly TN, Reed JE, Kearney PM, Reynolds K, Chen J, et al. Global disparities of hypertension prevalence and control: a systematic analysis of population-based studies from 90 countries. Circulation. 2016;134(6):441-450.

2. Whelton PK, Carey RM, Aronow WS, Casey DE, Jr., Collins KJ, Dennison Himmelfarb C, DePalma SM, et al. 2017 ACC/AHA/AAPA/ABC/ACPM/AGS/APhA/ASH/ ASPC/NMA/PCNA Guideline for the prevention, detection, evaluation, and management of high blood pressure in adults: executive summary: a report of the American College of Cardiology/American Heart Association Task Force on Clinical Practice Guidelines. Hypertension. 2018;71(6):1269-1324.

3. Williams B, Mancia G, Spiering W, Agabiti Rosei E, Azizi M, Burnier M, Clement DL, et al. 2018 ESC/ESH Guidelines for the management of arterial hypertension. Eur Heart J. 2018;39(33):3021-3104.

4. Rakugi H, Enya K, Sugiura K, Ikeda Y. Comparison of the efficacy and safety of azilsartan with that of candesartan cilexetil in Japanese patients with grade I-II essential hypertension: a randomized, double-blind clinical study. Hypertens Res. 2012;35(5):552-558.

5. White WB, Weber MA, Sica D, Bakris GL, Perez A, Cao 
C, Kupfer S. Effects of the angiotensin receptor blocker azilsartan medoxomil versus olmesartan and valsartan on ambulatory and clinic blood pressure in patients with stages 1 and 2 hypertension. Hypertension. 2011;57(3):413420.

6. Bakris GL, Sica D, Weber M, White WB, Roberts A, Perez A, Cao C, et al. The comparative effects of azilsartan medoxomil and olmesartan on ambulatory and clinic blood pressure. J Clin Hypertens (Greenwich). 2011;13(2):8188.

7. Ohshima K, Mogi M, Nakaoka H, Iwanami J, Min LJ, Kanno H, Tsukuda K, et al. Possible role of angiotensinconverting enzyme 2 and activation of angiotensin II type 2 receptor by angiotensin-(1-7) in improvement of vascular remodeling by angiotensin II type 1 receptor blockade. Hypertension. 2014;63(3):e53-59.

8. Kusumoto K, Igata H, Ojima M, Tsuboi A, Imanishi M, Yamaguchi F, Sakamoto H, et al. Antihypertensive, insulin-sensitising and renoprotective effects of a novel, potent and long-acting angiotensin II type 1 receptor blocker, azilsartan medoxomil, in rat and dog models. Eur J Pharmacol. 2011;669(1-3):84-93.

9. Iwai $\mathrm{M}$, Chen $\mathrm{R}$, Imura $\mathrm{Y}$, Horiuchi M. TAK-536, a new AT1 receptor blocker, improves glucose intolerance and adipocyte differentiation. Am J Hypertens. 2007;20(5):579-586.

10. Matsumoto S, Shimabukuro M, Fukuda D, Soeki T, Yamakawa K, Masuzaki H, Sata M. Azilsartan, an angiotensin II type 1 receptor blocker, restores endothelial function by reducing vascular inflammation and by increasing the phosphorylation ratio Ser(1177)/Thr(497) of endothelial nitric oxide synthase in diabetic mice. Cardiovasc Diabetol. 2014;13:30.

11. Kreutz R. Olmesartan/amlodipine: a review of its use in the management of hypertension. Vasc Health Risk Manag. 2011;7:183-192.

12. Matsui Y, Eguchi K, O'Rourke MF, Ishikawa J, Miyashita H, Shimada K, Kario K. Differential effects between a calcium channel blocker and a diuretic when used in combination with angiotensin II receptor blocker on central aortic pressure in hypertensive patients. Hypertension. 2009;54(4):716-723.
13. Lacourciere Y, Poirier L, Hebert D, Assouline L, Stolt P, Rehel B, Khder Y. Antihypertensive efficacy and tolerability of two fixed-dose combinations of valsartan and hydrochlorothiazide compared with valsartan monotherapy in patients with stage 2 or 3 systolic hypertension: an 8-week, randomized, double-blind, parallel-group trial. Clin Ther. 2005;27(7):1013-1021.

14. Lacourciere Y, Neutel JM, Schumacher H. Comparison of fixed-dose combinations of telmisartan/hydrochlorothiazide $40 / 12.5 \mathrm{mg}$ and $80 / 12.5 \mathrm{mg}$ and a fixed-dose combination of losartan/hydrochlorothiazide 50/12.5 $\mathrm{mg}$ in mild to moderate essential hypertension: pooled analysis of two multicenter, prospective, randomized, open-label, blinded-end point (PROBE) trials. Clin Ther. 2005;27(11):1795-1805.

15. Ogihara T, Kikuchi K, Matsuoka H, Fujita T, Higaki J, Horiuchi M, Imai Y, et al. The Japanese Society of Hypertension Guidelines for the management of hypertension (JSH 2009). Hypertens Res. 2009;32(1):3-107.

16. Miyoshi T, Suetsuna R, Tokunaga N, Kusaka M, Tsuzaki R, Koten K, Kunihisa K, et al. Effect of azilsartan on dayto-day variability in home blood pressure: a prospective multicenter clinical trial. J Clin Med Res. 2017;9(7):618623.

17. Imai Y, Otsuka K, Kawano Y, Shimada K, Hayashi H, Tochikubo O, Miyakawa M, et al. Japanese society of hypertension (JSH) guidelines for self-monitoring of blood pressure at home. Hypertens Res. 2003;26(10):771-782.

18. Shimosawa T, Gohchi K, Yatomi Y, Fujita T. Effectiveness of add-on low-dose diuretics in combination therapy for hypertension: losartan/hydrochlorothiazide vs. candesartan/amlodipine. Hypertens Res. 2007;30(9):831-837.

19. McInnes GT, O'Kane KP, Istad H, Keinanen-Kiukaanniemi S, Van Mierlo HF. Comparison of the AT1-receptor blocker, candesartan cilexetil, and the ACE inhibitor, lisinopril, in fixed combination with low dose hydrochlorothiazide in hypertensive patients. J Hum Hypertens. 2000;14(4):263-269.

20. Muntner P, Carey RM, Gidding S, Jones DW, Taler SJ, Wright JT, Jr., Whelton PK. Potential US population impact of the 2017 ACC/AHA High Blood Pressure Guideline. Circulation. 2018;137(2):109-118. 